\title{
Children's Astronomy. Development of the Shape of the Earth Concept in Polish Children between 5 and 10 Years of Age
}

\author{
Jan Amos Jelinek
}

Citation: Jelinek, J.A. Children's Astronomy. Development of the Shape of the Earth Concept in Polish Children between 5 and 10 Years of Age. Educ. Sci. 2021, 11, 75. https:// doi.org/10.3390/educsci11020075

\section{Academic Editor:}

Konstantinos Ravanis

Received: 22 January 2021

Accepted: 9 February 2021

Published: 14 February 2021

Publisher's Note: MDPI stays neutral with regard to jurisdictional claims in published maps and institutional affiliations.

Copyright: (C) 2021 by the author. Licensee MDPI, Basel, Switzerland. This article is an open access article distributed under the terms and conditions of the Creative Commons Attribution (CC BY) license (https:// creativecommons.org/licenses/by/ $4.0 /)$.
Institute of Assisted Human Development and Education, The Maria Grzegorzewska University, 02-353 Warsaw, Poland; jajelinek@aps.edu.pl

\begin{abstract}
The Earth's shape concept develops as consecutive cognitive problems (e.g., the location of people and trees on the spherical Earth) are gradually resolved. Establishing the order of problem solving may be important for the organisation of teaching situations. This study attempted to determine the sequence of problems to be resolved based on tasks included in the EARTH2 test. The study covered a group of 444 children between 5 and 10 years of age. It captured the order in which children solve cognitive problems on the way to constructing a science-like concept. The test results were compared with previous studies. The importance of cultural influences connected to significant differences $(24 \%)$ in test results was emphasised. Attention was drawn to the problem of the consistency of the mental model approach highlighted in the literature. The analysis of the individual sets of answers provided a high level of consistency of indications referring to the same model (36\%), emphasising the importance of the concept of mental models.
\end{abstract}

Keywords: shape of the Earth; conceptual development; mental models; astronomy; EARTH2 test; knowledge-as-elements; knowledge-as-theory; cultural differences

\section{Introduction}

The development of concepts about the shape of the Earth and its place in space in children consists in gradual departure from personal experience [1-3]. First, based on everyday experience, children construct the concept of a flat Earth, and then, as a result of collecting information transmitted culturally, they build more science-like concepts [4-7]. Although research into this process has been ongoing for several decades now [1,7-11], it seems that the issue of conceptual development with regard to the shape of the Earth is still not exhausted. Reasons for the current state of affairs are theoretical doubts about how children construct their knowledge and recently raised methodological issues related to criticism of the concept of mental models [12,13].

Proponents of the knowledge-as-theory concept [14-16] based on the legacy of Jean Piaget [17] came to the conclusion that children construct explanations that resemble scientific theories in terms of function and structure. Their conclusions were based on studies dominated by methods that use open questions $[1,18]$. When encouraged to make entire statements, children seem to present a logical explanation of astronomical objects and phenomena [7]. Vosniadou and Brewer [1] refer to these coherent explanations of the Earth's shape as mental models.

Personal experience is considered to be the foundation for creating mental models. Based on them, children construct concepts [15], which for reasons of consistency Vosniadou refers to as initial models. As children come into contact with adult explanations, they gradually begin to include them in their explanations, thus creating synthetic models. It is believed that changes in beliefs (restructurings) do not occur globally (as described by Piaget [19]), but rather within a certain domain, i.e., are domain specific [15]. Additionally, these restructurings do not happen smoothly, as a kind of resistance is observed [20]. In addition, such a change in beliefs does not involve elimination, but rather overwriting $[15,21]$. 
The transition from intuitions to scientific concepts is gradual, and the correctness of the beliefs constructed along the way (synthetic models) depends on many variables: (a) the amount of information available, in particular its quality and accuracy, (b) access to scientific knowledge and the level of competition from common sense knowledge, (c) the number of situations where children have the opportunity to reflect on the sphericity of the Earth and their mental capabilities [1,4,6,11,22-26].

Mental models of the Earth's shape by Vosniadou and Brewer have been confirmed in Western countries [11,27], and also recently in Poland [28]. However, due to some observed cultural differences, it seems important to verify the models before taking them into account. The method used in Polish studies was an interview, supported by practical activity—children built plasticine models of the Earth's shape and pushed minifigures into it to locate people on the planet. Based on the children's statements, three shapes of the Earth were identified: a sphere, a flat disc and a strongly flattened cuboid. In terms of location, five different concepts have been identified:

- People live on the surface of the Earth, which is a flat cuboid (two children),

- People live on the upper surface of the Earth, depicted as a flat disc (11 children),

- People live on the upper and lower surface of the Earth, depicted as a flat disc (one child),

- People only live at the top of the spherical Earth (nine children),

- People live on all sides of the spherical Earth (26 children).

The mental rules that guide children when explaining the shape of the Earth (support and flatness) and cosmological relations (relative locations and motions of objects) were also confirmed. In the process of conceptual development, these rules constitute an important element of shaping the concept of the Earth's sphericity and the day and night phenomenon.

The idea of mental models assumes that children constantly have a certain amount of information at their disposal, from which they form coherent concepts. Meanwhile, other researchers point out that children do not have a ready explanation at hand at all times, but create answers on the spur of the moment based on their experiencessuperficial interpretations of reality (p-prims [2]). Recent studies seem to provide evidence for the concept of knowledge-as-elements $[3,12,13]$. It is believed that when experiencing objects and phenomena, children store experiences and bits of information heard from adults (fragmentation [12]). On that basis, they formulate concepts which, however, are not internally as organised as theories. It is the degree of coherence and organisation that is the greatest difference between the concept of knowledge-as-theory and knowledge-aselements [17].

Vosniadou [21], while acknowledging the findings of the fragmentarists, stated that there is a part of children's explanations which does not change (she calls it a "framework"). She stated that permanent elements of the concept remain the same, while elements of this structure change. Vosniadou considered the shape of the Earth to be the framework, and the changeable elements include, among other things, the location of people and clouds. To verify the existence of models, proponents of the fragmentation theory used Vosniadou and Brewer's [1,29] mental models of the Earth's shape as a basis for a forced-choice test [13]. The authors of the test assumed that if the respondents adhered to one and the same representation of the Earth's shape in their answers, then one could indeed speak of stable mental models. The authors interpreted the results obtained as low consistency of children's indications and stressed the importance of the knowledge-as-elements concept.

It is in such a climate of debate that the EARTH2 test was created. The test consists of nine questions and a set of answers presented in the form of pictures which graphically correspond to mental models of Vosniadou and Brewer. It was assumed that the methods used to date, with open questions and analysis of children's creations (drawings and clay structures), are difficult to interpret $[24,30]$. It was assumed that the most reliable research tool would be a forced-choice test [13]. It was emphasised that this type of tool would make it possible to diagnose children's representations of the Earth's shape in an economic way. Furthermore, the fact that such tools tend to generate more indications of scientific 
answers was considered to be an added value $[10,24,30]$. However, opponents of the use of forced-choice tests point to its shortcomings. They stress that limiting the choice to five or six answers does not capture the reasoning of children [21]. It was pointed out that mental models depend on the influence of culture [22,23]. The use of forced-choice methods does not capture new concepts. In addition, the test also fails to identify the argumentation of children if the respondents should disagree with any of the answers. According to the authors of the test, if the questions are well designed, then children will have no doubt as to the choice of answers [13]. In order to verify the diagnostic utility of the test, a comparison was made between the test results and the interview, where statistical convergence was found.

However, on consideration, the test method used is problematic. First of all, solving cognitive problems by drawing and modelling, as well as just thinking about answering, can change beliefs [30]. The children who had previously completed the test with readymade pictures and then participated in the interview first had the opportunity to reflect on the questions (e.g., where people live on Earth, how they move), and then, after a suggestion of sorts, answered the same questions during the interview. When the children responded, they remembered the picture from the test and talked about it during the interview. Since the results were very convergent, it can be assumed that this was the case. What happened here was that the period between solving the test and participating in the interview was too short. Since the authors of EARTH2, do not specify a reminiscence period, it should be assumed that the high convergence in the test and interview results comes from the short period between the completion of the test and the children's participation in the interview. Perhaps the convergence would have been different if the children had been asked to provide full answers first and then had taken the test. This is evidenced by the fact that more correct answers were provided in forced-choice tests than for open-ended questions $[10,21]$.

Secondly, the interview involved a forced choice. The children were asked a series of nine questions (similar to those included in the EARTH2 test). The interview started by choosing one of a number of polystyrene foam models. Then, on the basis of the chosen model, the children were to answer questions about the location of people, trees, the way people move on Earth and so on. The choice of the polystyrene shape imposed a limitation on the possibility to study children's reasoning. During the test, the child was no longer able to change his/her choice to another model of the Earth's shape, although probably many would have wanted to, given that the test showed a low consistency of choices of a single model [13]. Changes in the choice of the Earth's shape were also reported in subsequent studies [31].

To date, the EARTH2 test has been used for two purposes: (a) to measure the increase in knowledge in experimental research and (b) to verify the theory of mental models. As a screening tool, the test was used by Yildiz, Güçhan Özgül and Saçkes [32]. It was instrumental in determining the educational impact of activities for children in experimental research. The study was conducted among 44 children aged 5-7 years in order to determine how they understand the day and night cycle and the shape of the Earth.

To test the concept of mental models, the EARTH2 test was used in studies conducted among Dutch [13] and Greek [31] children. The study was conducted on large groups of children, $\mathrm{N}=379$ and $\mathrm{N}=184$, aged 4 to 9 years and 6 to 8 years, respectively. The latent class analysis (LCA) revealed that children do not adhere to a single shape of the Earth, which was considered to contradict the consistency of mental models. The study did not reflect on the relationship between children's indications to individual questions in the test. It was limited to a general analysis of all responses as indicators of mental models. However, the analysis of individual choices-as described in this articleallowed us to draw deductions about the children's reasoning and determine the level of consistency, while relations between answers of different age groups provided information on conceptual development with regard to the shape of the Earth and the phenomenon of nightfall. 
If one wants to understand children's reasoning, one should examine the manner in which the EARTH2 test is carried out. The initial instructions do not reveal that children would answer questions about the shape of the Earth and related problems. Thus, the child recognises the context of the study as he or she learns the consecutive test questions. It is presumed that when the child hears the first question (What does the Earth look like?), he or she will realise the context of the whole study, e.g., the perspective of looking at the Earth in each subsequent question. When reading the consecutive questions, the researcher expects the child to guess the context and provide answers, whereas the atmosphere of silence and individual work during the test make it impossible for a child unable to understand the context to ask the researcher any questions. If the child grasps the context too late, then, even if they realise that the answer they gave to the previous question was wrong, he or she is no longer able to correct it, as the researcher is already reading the next question and expects the child to mark only one answer per question. So, a research situation with the use of a forced-choice test not only narrows down how one's own beliefs are formulated (they have to match one of the pictures/answers), but also limits the possibility to self-correct. Until now, this perspective seems to have escaped the researchers using this test because they focused on the analysis of children's responses as a whole.

The research methodology adopted to date does not raise any statistical concerns, but the interpretative direction does create a puzzle. There are several reasons for this: (a) the reliance on ready-made mental models seems to disregard cultural influences. Meanwhile, the development of children's astronomical concepts depends on access to scientific knowledge and the competing common sense knowledge [22,23]. (b) The argument about the importance of in-depth statistical analysis seems to marginalise the importance of qualitative research. In turn, the fact that statistical research is based on well-described mental models of the shape of the Earth in itself proves the importance of qualitative research. After all, the method of questioning supported by action (creating plasticine models and drawings) allows us to penetrate the child's way of thinking and describe their mental representation of the surrounding world [1,29]. (c) The decision not to analyse individual answers (indications) to the test questions proves that the research carried out served the purpose of a general understanding of children's reasoning without penetrating the problem of conceptual development with regard to the shape of the Earth. However, because we are still unable to fully describe the process of constructing basic astronomical concepts, e.g., the shape of the Earth [31], the failure to analyse individual questions narrows down an interesting research field.

This article presents an analysis of individual indications between questions, e.g., concerning the location and movement of people on Earth (questions 2 and 7 of EARTH2) and concerning the location of people, clouds and trees on Earth (questions 2, 3 and 5). In addition, the results were interpreted in relation to research that was previously carried out on another group of children by means of an interview with open questions and building a plasticine Earth, Moon and Sun as well as pushing minifigures into them to mark the location of people on Earth [28]. The results obtained in studies using the EARTH2 test will be supplemented by the conclusions of the studies conducted using an interview. The data collected on the basis of qualitative (interview) and quantitative (test) research will not be compared with each other, but will be supplemented with interpretations, in order to broaden the knowledge about the process of conceptual development with regard to the Earth's shape in children.

The study sought to answer the following questions: (1) where children between 5 and 10 years of age locate people and trees on the Earth as well as clouds in the sky, how they explain the movement of people and a ball on the Earth and the nightfall phenomenon; (2) how children's concepts change between the ages of 5 and 10; (3) how consistent are children's concepts when comparing children's answers to the individual questions in the EARTH2 test (but not all answers). It also sought to determine cultural differences based on a comparison of EARTH2 test results. 
For the purposes of this article, the term mental models will only be applied in relation to the answers/images included in the EARTH2 test. In other places, the term concept will be used or, in the context of development: intuitions, outlines of concepts and science-like concepts. The term intuitions is understood as the essence of everyday experience (intuitions correspond to initial models), outlines of concepts are understood as mental constructs which emerge as personal experience clashes against information received from adults (they correspond to synthetic models), while science-like concepts appear as outlines of concepts are refined and scientific knowledge is absorbed (they correspond with scientific models). The use of these terms (a) follows the course of human development (characteristic of mental models), (b) refers to the tradition of concepts as mental building materials [19,33], (c) bearing in mind the (presently) debatable consistency of mental models adopted in the definition of Vosniadou [1,21], allows us to safely describe the nature of constructing representations.

\section{Materials and Methods}

This study used the EARTH2 test, translated into Polish. It had been chosen because: (a) it is designed to establish children's representations of the shape of the Earth quickly. (b) The test questions contain a scientifically interesting set of cognitive problems that children have to solve on the way to constructing a science-like concept. (c) The research carried out among Polish children [28] did not reveal any mental models other than those described by Vosniadou and Brewer [1,29], based on which the test has been developed. The lack of differences has eliminated concerns about cultural differences.

The EARTH2 test contains nine questions, which are presented to children in the form of a 10-page booklet. Each question contains a set of five or six answers presented as pictures. It is assumed that by choosing a picture (graphic representation), the child indicates to the researcher a mental model corresponding to his/hers. The test involved handing out booklets to the children, having the researcher read out a series of questions and waiting for the children to choose one of the given answers/pictures.

Four hundred and forty-four children aged five to ten years $(M=7.6)$ participated in the study procedure. Among them, 99 children were five and six years old, 242 children were seven and eight years old and 103 children were nine and ten years old. In this group, there were 252 boys and 192 girls; 206 children came from a city (40,000 inhabitants) and the remaining 238 children from a village $10 \mathrm{~km}$ away.

\section{Results}

In the EARTH2 test, children were given ready-made answers/pictures and asked to select the one they considered the most appropriate. The children's detailed answers to all the test questions are presented in Table A1 (Appendix A). This table also includes results from studies among Dutch and Greek children, which will be summarised later in the article.

\subsection{Shape of the Earth}

To the first question: What does the Earth look like? the vast majority of children $(98.6 \%)$ responded that it was spherical in shape. Only a small percentage $(1.4 \%)$ marked a different shape of the Earth. It is surprising that all 5-year-olds, while selecting graphic representations, chose the one which emphasised the spherical character of the Earth. Similar results (96.6\%) were obtained in the control question (8) Which picture resembles the Earth best? I would like to add that in a study carried out using a lump of plasticine, only $71.4 \%$ (35 out of 49 respondents) thought that the Earth was spherical.

Table 1 summarises the answers to both questions. The first column contains schematic images of the shape of the Earth from the EARTH2 test, ordered from the scientific model to the initial model. Presenting the answers to question 8 , we give the number of children who marked pictures corresponding to the same model (i.e., the scientific model) in both 
questions. This summary shows the extent to which the children surveyed adhered to the pre-selected answers (consistency).

Table 1. Consistency of answers regarding the questions What does the Earth look like? (1) and Which picture resembles the Earth best? (8).

\begin{tabular}{|c|c|c|c|c|c|c|}
\hline \multirow{2}{*}{ Question 1} & \multirow{2}{*}{$\begin{array}{l}\text { Number of } \\
\text { Indications }\end{array}$} & \multirow{2}{*}{ Question 8} & \multirow{2}{*}{$\begin{array}{l}\text { Number of } \\
\text { Indications }{ }^{1}\end{array}$} & \multicolumn{3}{|c|}{ Age } \\
\hline & & & & $5-6$ & $7-8$ & 9-10 \\
\hline & $\begin{array}{c}438 \\
98.6 \%\end{array}$ & & $\begin{array}{c}426 \\
95.9 \%\end{array}$ & $94.9 \%$ & $95.5 \%$ & $98.1 \%$ \\
\hline 0 & $\begin{array}{c}4 \\
0.9 \%\end{array}$ & 0 & $\begin{array}{c}2 \\
0.5 \%\end{array}$ & & $0.4 \%$ & $1 \%$ \\
\hline & $\begin{array}{c}1 \\
0.2 \%\end{array}$ & & & & & \\
\hline & $\begin{array}{c}1 \\
0.2 \%\end{array}$ & & $\begin{array}{c}1 \\
0.2 \%\end{array}$ & & $0.4 \%$ & \\
\hline
\end{tabular}

${ }^{1}$ The percentages do not add up to $100 \%$ as they only represent the share of children who indicated the same shape of the Earth in questions 1 and 8.

It is important to mention that when solving the EARTH2 test, children in each age group pointed out that the question about the shape of the Earth had been asked before, which shows that they were aware of the nature of previous answers. This is important as the order in which the questions were asked influenced the answers. When asked questions 1 and 8, children who chose different graphic representations (pictures) either could not remember the questions or were unsure about the shape of the Earth.

The number of indications of the spherical shape of the Earth changed as children answered the subsequent questions. When they answered a question about the location and movement of people and objects, they would gradually abandon indications of spherical Earth pictures. The details are presented in Table 2. In the test, e.g., in question 2: Which picture shows best where the people live on the Earth? the spherical Earth was represented by two pictures: (a) people live on all sides of the Earth (scientific model) and (b) people live only at the top of the Earth (synthetic model), and the following table includes indications for both answers/pictures.

There were $30 \%$ of children who consistently indicated the Earth as a sphere in all test questions (Choose the picture which best...). The number of indications in each age group increased from $15 \%$ in five- and six-year-olds to $49 \%$ in nine- and ten-year-olds. These children had already abandoned intuitions (the Earth is flat) in favour of outlines of concepts (the Earth is spherical). It turned out that the older a child is, the more certain he or she is that the Earth is spherical.

Interestingly, when in the analysis answers to questions 1 and 8, i.e., direct questions about the shape of the Earth, were skipped, $5.9 \%$ of all children chose pictures depicting a flat Earth. In questions 1 and 8, these children, presumably wanting to meet the adult's expectations, chose a picture depicting a spherical Earth and/or a spherical Earth image is familiar to them (books, TV). 
Table 2. Share of indications of pictures depicting a spherical Earth.

\begin{tabular}{|c|c|c|c|c|}
\hline \multirow{2}{*}{$\begin{array}{l}\text { Question (Number of Answers Presenting the } \\
\text { Spherical Image of the Earth). }\end{array}$} & \multirow{2}{*}{$\begin{array}{l}\text { Percentage of } \\
\text { Indications }\end{array}$} & \multicolumn{3}{|c|}{ Age } \\
\hline & & $5-6$ & $7-8$ & 9-10 \\
\hline 1. What does the Earth look like? (hollow, scientific) & $98.6 \%$ & $100 \%$ & $97.9 \%$ & $99.0 \%$ \\
\hline $\begin{array}{l}\text { 2. Which picture shows best where the people live on } \\
\text { the Earth? (hollow, scientific) }\end{array}$ & $83.8 \%$ & $79.8 \%$ & $83.1 \%$ & $89.3 \%$ \\
\hline $\begin{array}{l}\text { 3. Which picture shows best where the clouds are? } \\
\text { (hollow, scientific) }\end{array}$ & $81.1 \%$ & $76.8 \%$ & $79.8 \%$ & $88.3 \%$ \\
\hline $\begin{array}{l}\text { 4. Which picture shows best what happens when a } \\
\text { giant kicks a ball real hard? (hollow, scientific) }\end{array}$ & $68.2 \%$ & $63.6 \%$ & $68.2 \%$ & $72.8 \%$ \\
\hline $\begin{array}{l}\text { 5. Which picture shows best where the trees are on the } \\
\text { Earth? (hollow, scientific) }\end{array}$ & $62.2 \%$ & $53.5 \%$ & $62.4 \%$ & $69.9 \%$ \\
\hline $\begin{array}{l}\text { 6. Where is the Sun at night? (hollow, no gravity, } \\
\text { scientific) }\end{array}$ & $46.4 \%$ & $27.3 \%$ & $46.7 \%$ & $64.1 \%$ \\
\hline $\begin{array}{l}\text { 7. What happens when you walk along a straight line } \\
\text { for a very long time? (hollow, scientific) }\end{array}$ & $45.0 \%$ & $27.3 \%$ & $45.4 \%$ & $62.1 \%$ \\
\hline $\begin{array}{l}\text { 8. Which picture resembles the Earth best? (dual } \\
\text { Earth, hollow, scientific) }\end{array}$ & $44.1 \%$ & $27.3 \%$ & $43.4 \%$ & $62.1 \%$ \\
\hline $\begin{array}{l}\text { 9. Which picture shows best how night falls? (hollow, } \\
\text { scientific) }\end{array}$ & $30.2 \%$ & $15.2 \%$ & $28.1 \%$ & $49.5 \%$ \\
\hline
\end{tabular}

\subsection{Location and Movement of People on Earth}

In the EARTH2 test, children answered the question: (2) Which picture shows best where the people live on the Earth? A surprisingly large number of children $(62.6 \%)$ chose the picture that depicted people positioned around the planet (Table A1 in Appendix A). In a study in which, after forming the shape of the Earth out of plasticine, children pushed Lego minifigures into it, only $53.1 \%$ ( 26 out of 49 children) placed people around the spherical Earth and were able to justify it verbally.

However, comparing question (2) Which picture shows best where the people live on the Earth? and question (7) What happens when you walk along a straight line for a very long time? (Table 3), it turned out that more than $13 \%$ of the children abandoned the scientific answer.

Table 3. Where people live and how they move on Earth.

\begin{tabular}{|c|c|c|c|c|c|c|}
\hline \multirow{2}{*}{ Question 2} & \multirow{2}{*}{$\begin{array}{l}\text { Number of } \\
\text { Indications }\end{array}$} & \multirow{2}{*}{ Question 7} & \multirow{2}{*}{$\begin{array}{l}\text { Number of } \\
\text { Indications }\end{array}$} & \multicolumn{3}{|c|}{ Age } \\
\hline & & & & $5-6$ & $7-8$ & $9-10$ \\
\hline & $\begin{array}{c}278 \\
62.6 \%\end{array}$ & & $\begin{array}{c}218 \\
49.1 \%\end{array}$ & $28.3 \%$ & $49.6 \%$ & $68 \%$ \\
\hline & $\begin{array}{c}99 \\
22.3 \%\end{array}$ & & $\begin{array}{c}15 \\
3.4 \%\end{array}$ & $8.1 \%$ & $2.9 \%$ & \\
\hline & $\begin{array}{c}5 \\
1 \%\end{array}$ & & 0 & & & \\
\hline & $\begin{array}{c}26 \\
5.9 \%\end{array}$ & & $\begin{array}{c}9 \\
2 \%\end{array}$ & $1 \%$ & $2.9 \%$ & $1 \%$ \\
\hline & $\begin{array}{l}36 \\
8 \%\end{array}$ & & $\begin{array}{c}7 \\
1.6 \%\end{array}$ & $2 \%$ & $1.7 \%$ & $1 \%$ \\
\hline & & & $\begin{array}{c}3 \\
0.7 \%\end{array}$ & $2 \%$ & $0.4 \%$ & \\
\hline
\end{tabular}

$\overline{{ }^{1} \text { The percentages do not add up to } 100 \% \text { as they only represent the share of children who indicated the same }}$ shape of the Earth in questions 2 and 7. 
Locating humans on Earth requires that, in their reasoning, children combine: (a) a belief in the sphericity of the Earth (for many children, the idea of a flat Earth is closer due to direct experience) and (b) an elementary understanding of how gravity works. It can include intuitions (objects can also fall from spherical objects) and outlines of concepts (there is something at the centre of the Earth that attracts objects and therefore they do not fall off). The data in Table 4 show that the number of children who are consistently guided by the belief that the Earth is spherical increases with age. This includes an intuitive understanding of the phenomenon of Earth's magnetism, which implies that people can move around the Earth's surface without fear of falling off the Earth and floating into space.

Table 4. Consistency of answers to questions about the location of people, trees and clouds.

\begin{tabular}{|c|c|c|c|c|c|}
\hline Question 2 & $\begin{array}{l}\text { Number of } \\
\text { Indications }\end{array}$ & Question 3 & $\begin{array}{c}\text { Number of } \\
\text { Indications }{ }^{1}\end{array}$ & Question 5 & $\begin{array}{l}\text { Number of } \\
\text { Indications }\end{array}$ \\
\hline & $\begin{array}{c}278 \\
62.6 \%\end{array}$ & & $\begin{array}{c}207 \\
46.6 \%\end{array}$ & & $\begin{array}{c}157 \\
35.4 \%\end{array}$ \\
\hline & $\begin{array}{c}99 \\
22.3 \%\end{array}$ & & $\begin{array}{c}51 \\
11.5 \%\end{array}$ & & $\begin{array}{c}35 \\
7.9 \%\end{array}$ \\
\hline & $\begin{array}{c}5 \\
1.1 \%\end{array}$ & & $\begin{array}{c}5 \\
1.1 \%\end{array}$ & & $\begin{array}{c}1 \\
0.2 \%\end{array}$ \\
\hline & $\begin{array}{c}26 \\
5.9 \%\end{array}$ & & $\begin{array}{c}6 \\
1.4 \%\end{array}$ & & $\begin{array}{c}5 \\
1.1 \%\end{array}$ \\
\hline & $\begin{array}{l}36 \\
8 \%\end{array}$ & & $\begin{array}{c}10 \\
2.3 \%\end{array}$ & & 10 \\
\hline
\end{tabular}

${ }^{1}$ The percentages do not add up to $100 \%$ as they only represent the share of children who indicated the same shape of the Earth in questions 2 and $3 .{ }^{2}$ The percentages do not add up to $100 \%$ as they only represent the share of children who indicated the same shape of the Earth in questions 2, 3 and 5.

It is interesting that out of 99 children who, in question 2, stated that humans only lived at the top of the planet, as many as 63 also claimed that it was possible to go around the spherical Earth and it was impossible to fall down (they chose the scientific model). This type of inconsistency is related to solving the problem of Earth's gravity and its influence on human life. These children probably tried to recall any available information about cases of man falling off the Earth, and since they found none, they decided that it was impossible.

The analysis of indications of 62 children (14\% of respondents) who selected a flat model of the Earth in the test has shown that only $4 \%$ were consistent in choosing this shape of the Earth throughout the study.

\subsection{Location of People, Trees and Clouds}

In the EARTH2 test, children answered the questions: Which picture shows best where the people live on the Earth? (question 2), Which picture shows best where the clouds are? (question 3) and Which picture shows best where the trees are on the Earth? (question 5). The numbers of indications for each of these questions separately can be found in Table A1 (Appendix A). In terms of content, the issues addressed by these questions are related. Clouds float in space at a certain height and can be interpreted differently from the location of people or trees on the Earth. However, by comparing the answers to these questions, it is possible to establish what guides children in interpreting the location of these objects. 
Table 4 presents the number of children who showed consistency when choosing answers/pictures to the questions listed. The first column shows the graphic representations of the location of people on the Earth related to question 2 of the EARTH2 test, together with the number of indications to each answer. The following columns show the answers and the number of children who adhered to the same choice throughout the test.

The data in Table 5 show that more than one third (35.4\%) of all children surveyed (aged 5 to 10) are so sure that the Earth is spherical that they can draw inferences about the location of people and trees on the Earth and clouds in the sky. These children chose pictures that show that people and trees are located around the spherical Earth, and clouds in the sky are visible from anywhere on Earth. This astronomical knowledge was represented by both 5- and 6-year-olds (16\%), 7- and 8-year-olds (33.1\%) and 9- and 10-year-olds (59.2\%).

Table 5. Where people live and how they move on Earth.

\begin{tabular}{|c|c|c|c|c|c|c|}
\hline \multirow{2}{*}{ Question 4} & \multirow{2}{*}{$\begin{array}{l}\text { Number of } \\
\text { Indications }\end{array}$} & \multirow{2}{*}{ Question 7} & \multirow{2}{*}{$\begin{array}{l}\text { Number of } \\
\text { Indications }{ }^{1}\end{array}$} & \multicolumn{3}{|c|}{ Age } \\
\hline & & & & $5-6$ & $7-8$ & $9-10$ \\
\hline & $\begin{array}{c}224 \\
50.5 \%\end{array}$ & & $\begin{array}{c}204 \\
45.9 \%\end{array}$ & $31.3 \%$ & $47.1 \%$ & $57.3 \%$ \\
\hline & $\begin{array}{c}122 \\
27.5 \%\end{array}$ & & $\begin{array}{c}34 \\
7.7 \%\end{array}$ & $13 \%$ & $7.9 \%$ & $1.9 \%$ \\
\hline & $\begin{array}{c}16 \\
3.6 \%\end{array}$ & & $\begin{array}{c}1 \\
0.2 \%\end{array}$ & $1 \%$ & & \\
\hline & $\begin{array}{c}34 \\
7.7 \%\end{array}$ & & $\begin{array}{c}16 \\
3.6 \%\end{array}$ & $2 \%$ & $4.5 \%$ & $2.9 \%$ \\
\hline & $\begin{array}{c}35 \\
7.9 \%\end{array}$ & & $\begin{array}{c}11 \\
2.5 \%\end{array}$ & $2 \%$ & $2.9 \%$ & $1.9 \%$ \\
\hline$t$ & $\begin{array}{c}13 \\
2.9 \%\end{array}$ & 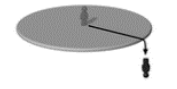 & $\begin{array}{c}1 \\
0.2 \%\end{array}$ & & $0.4 \%$ & \\
\hline
\end{tabular}

${ }^{1}$ The percentages do not add up to $100 \%$ as they only represent the share of children who indicated the same shape of the Earth in questions 4 and 7.

In the next two rows of the table, data are given for the children who, for the three questions listed above, chose pictures depicting the Earth as a sphere or a slightly flattened ball. However, they only located people and trees on the upper or on the upper and lower surface of the flattened Earth. They located clouds in the sky, which enveloped the Earth only in specific places-at the top or at the bottom and the top of the Earth. This was the case for $8 \%$ of the children, i.e., 36 respondents.

The last two rows contain data on 15 children (just over $3 \%$ of all respondents) who, in the EARTH2 test, chose images of a flat Earth with people and trees located on a flat surface, and clouds located in the sky visible from the flat Earth.

\subsection{Movement of a Ball and People on Earth}

In the EARTH2 test, there are two separate questions about the movement of people and a kicked ball on the surface of the Earth. After hearing each question, children were asked to choose one of several pictures which they thought was correct. The data for these responses are given in Table 5. The first column contains answers to question (4) Which picture shows best what happens when a giant kicks a ball real hard? and the second one, answers to question (7) What happens when you walk along a straight line for a very long time?

Answering questions about movements on the Earth's surface requires children to have some awareness of gravity. In Polish schools, the phenomenon of gravity is not discussed until the fourth grade, so the children surveyed did not have the opportunity 
to learn about it at school. It is also difficult to expect parents (in out-of-school education) to explain the consequences of this phenomenon to the child. Nor is the phenomenon of gravity introduced to children in the available publications on natural phenomena.

Nevertheless, the data in the first row of Table 6 show that almost half of the respondents $(45.9 \%$ ) consistently state that people and objects (a ball) will move across the entire surface of the spherical Earth. These children use science-like concepts when considering the movement of objects on the surface of the Earth. The other children surveyed did not share that opinion, as evidenced by the data in other rows of the table. Therefore:

Table 6. Consistency of answers to the question about the location of the Sun at night as well as nightfall.

\begin{tabular}{|c|c|c|c|c|c|c|}
\hline \multirow{2}{*}{ Question 6} & \multirow{2}{*}{$\begin{array}{l}\text { Number of } \\
\text { Indications }\end{array}$} & \multirow{2}{*}{ Question 9} & \multirow{2}{*}{$\begin{array}{l}\text { Number of } \\
\text { Indications }{ }^{1}\end{array}$} & \multicolumn{3}{|c|}{ Age } \\
\hline & & & & $5-6$ & $7-8$ & 9-10 \\
\hline & $\begin{array}{c}241 \\
54.3 \%\end{array}$ & & $\begin{array}{c}69 \\
15.5 \%\end{array}$ & $4 \%$ & $15.3 \%$ & $27.2 \%$ \\
\hline & $\begin{array}{c}46 \\
10.4 \%\end{array}$ & & $\begin{array}{c}18 \\
4.1 \%\end{array}$ & $3 \%$ & $4.5 \%$ & $3.9 \%$ \\
\hline & $\begin{array}{c}33 \\
7.4 \%\end{array}$ & & $\begin{array}{c}5 \\
1.1 \%\end{array}$ & $2 \%$ & $1.2 \%$ & \\
\hline & $\begin{array}{c}87 \\
19.6 \%\end{array}$ & & $\begin{array}{c}56 \\
12.6 \%\end{array}$ & $21.2 \%$ & $12.8 \%$ & $3.9 \%$ \\
\hline ب & $\begin{array}{c}37 \\
8.9 \%\end{array}$ & & $\begin{array}{c}15 \\
3.4 \%\end{array}$ & $6 \%$ & $3.7 \%$ & \\
\hline
\end{tabular}

1 The percentages do not add up to $100 \%$ as they only represent the share of children who indicated the same shape of the Earth in questions 6 and 9.

- the second and third rows contain data on the number of children who believed that the Earth was round or sphere-like in shape, but at the same time believed that it was possible to fall off the Earth. These children (35) showed constant beliefs in relation to the movement of a ball and people on the surface, however, when marking pictures they were convinced that the Earth had a boundary from which one could fall.

- the fourth, fifth and sixth rows contain data on the number of children who believed that the Earth was flat and that both humans and balls move only on its upper part. The same applies to the views of children who believe that if people and balls do not stop at the edge of the disk, they might fall off it.

The greatest inconsistency in the application of beliefs about the movement of a ball and people on Earth was observed in the synthetic models. Over $27 \%$ of the children believed that a ball could fall off the Earth, but only $7.7 \%$ of the children believed that the same could happen to humans. Seventy children thought that while a ball could fall off the Earth, a human being would not. The difference, possibly, may relate to the fact that the ball is inanimate or still, as opposed to a human being. Probably, if the order of questions had been different (e.g., the question about the way people move first, and then the one about the ball second), the results would have been different.

\subsection{The Phenomenon of Day and Night}

What children think about the phenomena of day and night can be established by comparing answers to the questions Where is the Sun at night? (6) and Which picture shows best how night falls? (9). Data on the consistency of picture choices can be found in Table 6. 
In explaining the phenomenon of nightfall, children show the greatest inconsistency. In all previous statements, the inconsistencies applied to synthetic models; here, the problem applies to the scientific model. Only $15.5 \%$ of respondents consistently used the scientific model in questions about the night. The indications of the majority of the remaining children, broadly speaking, were divided between two answers/pictures. Of all respondents, $18.9 \%$ (84 children) indicated a picture in which the Sun moves along the top edge, and $16.4 \%$ (73) of the children indicated a picture in which the Sun sets over the horizon.

The data in Table 7 show that about $4 \%$ of the respondents were convinced that the Earth is a sphere, but did not associate the brightness of the day with sunlight. The data in the third, fourth and fifth row indicate that about $17 \%$ of the children chose pictures showing different variants of a flat Earth with the Sun located above the surface of such an Earth.

Table 7. Percentage of picture choices by age group.

\begin{tabular}{|c|c|c|c|c|}
\hline \multirow{2}{*}{ Question } & \multirow{2}{*}{ Model } & \multicolumn{3}{|c|}{ Age } \\
\hline & & $5-6$ & $7-8$ & $9-10$ \\
\hline \multirow{3}{*}{ 1. What does the Earth look like? } & Initial & 0.0 & 0.4 & 0.0 \\
\hline & Synthetic & 0.0 & 1.7 & 1.0 \\
\hline & Scientific & 100 & 97.9 & 99.0 \\
\hline \multirow{3}{*}{$\begin{array}{l}\text { 2. Which picture shows best } \\
\text { where the people live on the } \\
\text { Earth? }\end{array}$} & Initial & 15.2 & 7.0 & 3.9 \\
\hline & Synthetic & 36.3 & 31.8 & 16.5 \\
\hline & Scientific & 48.5 & 61.2 & 79.6 \\
\hline \multirow{3}{*}{$\begin{array}{l}\text { 3. Which picture shows best } \\
\text { where the clouds are? }\end{array}$} & Initial & 5.0 & 4.1 & 1.0 \\
\hline & Synthetic & 55.5 & 34.3 & 19.4 \\
\hline & Scientific & 39.4 & 61.6 & 79.6 \\
\hline \multirow{3}{*}{$\begin{array}{l}\text { 4. Which picture shows best } \\
\text { what happens when a giant kicks } \\
\text { a ball real hard? }\end{array}$} & Initial & 9.0 & 11.2 & 11.7 \\
\hline & Synthetic & 48.6 & 38.8 & 29.2 \\
\hline & Scientific & 42.4 & 50.0 & 59.2 \\
\hline \multirow{3}{*}{$\begin{array}{l}\text { 5. Which picture shows best } \\
\text { where the trees are on the Earth? }\end{array}$} & Initial & 23.2 & 12.4 & 7.8 \\
\hline & Synthetic & 48.4 & 36.0 & 27.2 \\
\hline & Scientific & 28.3 & 51.7 & 65.0 \\
\hline \multirow{3}{*}{ 6. Where is the Sun at night? } & Initial & 53.5 & 25.0 & 9.7 \\
\hline & Synthetic & 22.2 & 17.4 & 14.5 \\
\hline & Scientific & 24.2 & 57.4 & 75.7 \\
\hline \multirow{3}{*}{$\begin{array}{l}\text { 7. What happens when you walk } \\
\text { along a straight line for a very } \\
\text { long time? }\end{array}$} & Initial & 6.0 & 1.7 & 0.0 \\
\hline & Synthetic & 34.3 & 26.8 & 17.4 \\
\hline & Scientific & 59.6 & 71.5 & 82.0 \\
\hline \multirow{3}{*}{$\begin{array}{l}\text { 8. Which picture resembles the } \\
\text { Earth best? }\end{array}$} & Initial & 2.0 & 1.2 & 1.9 \\
\hline & Synthetic & 3.0 & 2.1 & 0.0 \\
\hline & Scientific & 94.9 & 96.7 & 98.1 \\
\hline \multirow{3}{*}{$\begin{array}{l}\text { 9. Which picture shows best how } \\
\text { night falls? }\end{array}$} & Initial & 59.6 & 49.6 & 35.0 \\
\hline & Synthetic & 27.3 & 31.8 & 32.0 \\
\hline & Scientific & 13.1 & 18.6 & 34.0 \\
\hline \multirow[t]{3}{*}{ Total: } & Initial & 19.3 & 12.6 & 7.9 \\
\hline & Synthetic & 30.6 & 24.5 & 17.5 \\
\hline & Scientific & 50.1 & 62.9 & 74.6 \\
\hline
\end{tabular}

\subsection{Breakdown of Mental Models by Age}

Detailed data on the frequency with which children chose pictures corresponding to intuitions, conceptual outlines and science-like concepts respectively are presented in Table 7. It summarises the distribution of individual mental models in each age group.

The number of correct ideas about the shape of the Earth, the location of people, trees and clouds on Earth, the force of gravity and the phenomena of day and night increases 
in children between 5 and 10 years of age. The study also showed the intensity of such changes in children. It turns out that this development is not identical across all the scopes tested with regard to astronomical objects and phenomena. With increasing age, the number of science-like answers increases in the following areas: ideas about the location of people, trees and clouds, determining the possibility of human movement on Earth and the behaviour of objects on the Earth's surface (kicked ball). Parallel to the increase in the number of scientific explanations, the number of children who prefer preliminary and simplified models on the same topics decreases.

These changes apply to all models except for the hollow Earth model. Indications to pictures depicting, e.g., people living in the middle of a hollow Earth, trees and clouds inside the dome of the Earth, remain low (approx. 6-10\%) at all studied developmental stages. It seems that imagining a flat space enclosed by a dome makes it relatively easy to explain certain phenomena, such as those related to the force of gravity. It seems that children do not think about the direction of the force (or its source) and rely on information they heard from adults that it was impossible to fall off the Earth. Since it is easy to fall off the plane of a disc (after all, it resembles the surface of a table), there must be another image of the flatness of the Earth, which contains a kind of boundary that cannot be crossed. The curvature of a sphere seen on the inside-and creating the impression of a wall prevents a fall from the planet. In this type of reasoning, the problem of gravity is not solved, it is simply eliminated. It is also interesting to note that most references to the flatness of the Earth appear in response to the question about explaining the phenomenon of nightfall. This may be due to a different understanding of the test questions (Where is the Sun at night? and Which picture shows best how night falls?).

An analysis of children's choices of pictures depicting the shape of the Earth, the location of objects (people and things) and the way they move on the Earth, the relationship between the Earth and the Sun and the phenomena of day and night showed that, with increasing age, there are significant changes in the choice of graphic representations (in the EARTH2 test). The youngest respondents (5- and 6-year-olds) were significantly more likely to choose pictures corresponding to everyday experiences (initial models), while older children were more likely to choose pictures that represented a phenomenon in a more generalised way and linked to a scientific explanation. As children get older, they use less and less intuition and can use more science-like concepts to explain phenomena, whereas the percentages show that more than half of the youngest children display scientific models. Among the oldest respondents, non-scientific mental models persist until the age of 10 .

\subsection{The Order of Solving Problems in the Process of Forming the Concept of the Earth's Shape}

The test questions were designed to address areas where the shape of the Earth poses a significant cognitive problem. In the process of constructing the concept of a spherical Earth, children must resolve each of these problems to build a science-like concept. Research has shown that the number of children who indicate scientific models increases with age. However, since the percentage of indications varies from question to question, their analysis can provide information on the order in which these problems are resolved. It was assumed that if, in a given age group, the percentage of correct answers is higher for one of two questions (problems), it means that children resolved one problem earlier than the other. In this way, by comparing the percentage of correct answers to each of the test questions, it will be possible to determine the order of solving problems in the process of forming the concept of the Earth's shape. The explanation adopted here can be described as a gradual integration of the concept of a spherical Earth into the conceptual structure, which was previously dominated by the concept of a flat Earth.

Three types of questions were included in the analysis: (a) the location of people, trees and clouds, (b) the movement of objects on the Earth's surface (people and a kicked ball) and (c) the day and night phenomena. The percentages of correct answers to all test questions are summarised in Figure 1. 


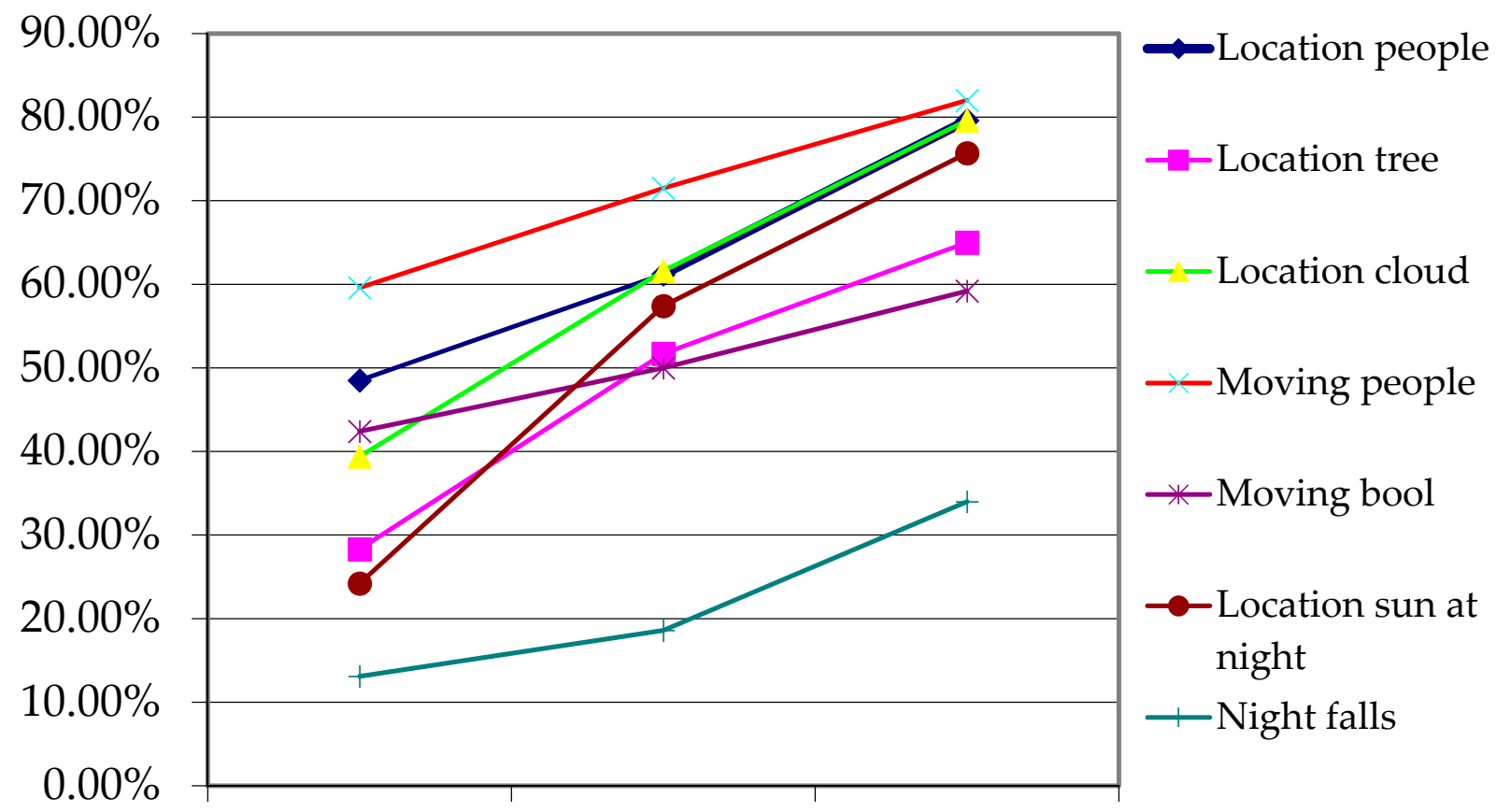

Age 5 and 6 Age 7 and 8 Age 9 and 10

Figure 1. Indication of scientific models in relation to age.

The diagonal lines in the graph show an upward trend in the number of correct indications for all questions analysed. The analysis of the questions concerning locations has shown that, in each age group:

- in explaining the location of people on the Earth, the largest group of children is guided by the belief in sphericity of the Earth. This is probably due to the confrontation of personal experience with knowledge about the consequences of the Earth's sphericity;

- slightly fewer children were able to transfer the conclusion about the location of people on a spherical Earth to the location of clouds in the sky wrapping around the Earth. Perhaps the obstacle is the everyday experience of observing the movement of clouds in the sky, which seems to confirm the intuition about the flatness of the Earth;

- the smallest group of children is able to transfer an inference about the location of people to the location of trees on Earth. This is probably due to the fact that children have rarely (or not at all) had the opportunity to consider the location of trees on the globe.

The fact that trees were the most difficult to locate on Earth, then clouds, with people being the easiest leads to the conclusion that these are the steps by which the children's minds fit the concept of a spherical Earth into their conceptual structure in terms of locating objects on the Earth's surface. It solves the problem of locating people first, then clouds and then trees. This is probably also influenced by images available to children, e.g., pictures of the Earth as seen from space, where clouds surround the blue planet (cultural influence).

Similar results are provided by the analysis of the movement of people and a ball on Earth. Children first construct an image of the movement of people on the surface of a spherical Earth, and then infer the movement of a ball.

In terms of locating the Sun at night and nightfall, there are clear differences. Children first provide a location for the Sun at night, and only later come to understand the phenomenon of nightfall.

Comparing the process of locating objects, their movement on the Earth's surface and the phenomenon of day and night, it turned out that children first come to identify how people move on the spherical Earth and then locate people on the Earth. Next, they also locate clouds, the Sun at night and trees. Finally, they work out how a kicked ball 
moves. The phenomenon of nightfall is the last item for children in every age group. The explanation described here, however, seems to hold true only for the answers/pictures included in the EARTH2 test. It must be assumed that if the pictures were different or the order of the questions in the test were changed, the results might be different.

\section{Discussion}

\subsection{Development of the Concept of the Earth's Shape}

Research conducted among Polish children has shown that all 5-year-old respondents pointed to the Earth in the shape of a sphere, but $2 / 3$ of them gradually give up the spherical shape when explaining the location of people, trees and clouds, as well as indicating the movement of people and a ball, and explaining the phenomenon of nightfall. The number of children who use science-like concepts increases with age. It was also found that non-scientific concepts still persist in 10-year-old children. This confirms previous findings $[4,5,34]$.

It was also found that children first construct the concept of a spherical Earth and then the Earth-Sun relationship. It was assumed that the concept of the Earth's shape is constructed by gradually fitting the concept to the current knowledge structure. The order of resolving cognitive problems was established. It was assumed that problem solving involves re-establishing the location of people and objects on the surface and their movement. It was found that children first solve the problem of how people move on Earth, then their location, as well as the location of clouds, the Sun at night and trees. Finally, children match the way a kicked ball moves on Earth and the phenomenon of nightfall. These data have not yet been established in an acceptable way and need to be verified, especially as the results may be limited by the construction of the research tool and dependent on cultural influences.

The research findings may be relevant in organising educational activities for children to build basic astronomical concepts. Attention to the sequence of problems to be addressed during organised activities may contribute to increased educational effectiveness.

\subsection{The Context of Cultural Differences}

The context of cultural differences can be observed when the same tools are used with children from different countries. Such a comparison is encouraged by the authors of the EARTH2 test [13]. Unfortunately, as the indications have been grouped solely according to mental models [32] and no distinctions have been made between answers of different age groups to the test $[13,31]$, a detailed analysis of the data is not possible. For this reason, the analysis will be limited to all age groups surveyed. A full summary of the results is presented in Table A1 (Appendix A). The results are presented in the chronological order in which they were obtained.

Shape of the Earth. As for the first question about the shape of the Earth, in a study conducted among Dutch children, $81 \%$ chose the spherical shape of the Earth, while 10\% of the children indicated the hollow sphere model [13]. In a Greek study, the spherical Earth was indicated by $94.6 \%$, while the hollow sphere model was indicated by $2.2 \%$ of respondents [31]. The spherical model of the Earth was indicated by $98.6 \%$ of Polish children, and the hollow sphere model was not indicated even once. As regards the control question (8) about the shape of the Earth, in the Dutch study, $81 \%$ of children indicated the spherical shape of the Earth, and 5.5\% the hollow sphere model. In the Greek study, the results were almost $93 \%$ and 5\%, respectively, and in the Polish study, $96.6 \%$ and $0.5 \%$, respectively.

Location of people, clouds and trees. A similar difference can be observed in questions 2, 3 and 5. In the question about the location of people on Earth (question 2), differences in the number of indications of scientific models are as follows: $44.6 \%$ of Dutch children and $54.3 \%$ of Greek children and $62.6 \%$ of Polish children. As regards the question about the location of clouds (question 3), scientific models were indicated by $45.1 \%$ of the Dutch children, 41.8 of the Greek children and $60.8 \%$ of the Polish children. As for the question 
about the location of the trees (question 5), $42.4 \%$ of the Dutch children and the same percentage of the Greek children pointed to the scientific model, while among the Polish children, this model was indicated by slightly more than $49.5 \%$.

Movement of a ball and people on Earth. To question 4, almost $40 \%$ of the Dutch and $35 \%$ of the Greek children pointed to a model where the ball goes around the Earth. In Poland, it was more than half of the respondents (50.5\%). In question 7 about the movement of people on the Earth, the difference was the greatest and amounted to $23.9 \%$. For this question, $47.5 \%$ of Dutch and $58.7 \%$ of Greek children indicated that people can go around the Earth, and the same answer was given by more than $71.4 \%$ of the Polish respondents.

Day and night phenomenon. In the question (6) about the location of the Sun at night, $40 \%$ of the Dutch and Greek children gave the correct answer, and the same answer was given by $54.3 \%$ of the Polish children. As for the control question (9) about nightfall, the results showed the smallest difference. More than $12 \%$ of the Dutch children pointed to the scientific model, while among the Greek and Polish children, there were $20.7 \%$ such indications.

A comparison of the results of individual test questions showed that differences between the Polish and Dutch children ranged from $7.1 \%$ to $23.9 \%$ and between the Polish and Greek tests from $0.5 \%$ to $19 \%$. A difference of almost $24 \%$ is significant. The question may arise whether this is due to the difference in age of the children surveyed. The Dutch study was carried out with children from 4 to 9 years old, the Greek study involved children from 6 to 9 years old and the Polish study involved children from 5 to 10 years old. However, the difference in the average age of the children surveyed seems to contradict this. In the Dutch study, it was $M=7.2$, in the Greek study $M=6.9$ and in the Polish study $M=7.6$. This suggests, therefore, that it is not age but cultural differences that can have such a significant impact on different indications in the test.

It is possible that differences in the results are significantly influenced by education (including home education) or even toys. In Poland, it is rare to find children playing with, for example, a snow globe. A snow globe is a glass sphere filled with water and white pieces of material which, when shaken, resemble falling snowflakes. Perhaps Dutch children are more likely to use these toys and associate their design with the picture in the test depicting a hollow sphere. This may explain why in the Polish study none of the children indicated this model, while in the Dutch study as many as $10 \%$ of the children did.

Differences in the EARTH2 test results confirm the effect of cultural influences [6,22-24]. Relatively small differences in geographical location between the countries in which the studies were conducted suggest that actual differences in results may be even greater if more remote countries or those where access to the media is more limited were included. It may also be relevant that the mental models that formed the basis of the EARTH2 test were developed in the 1990s. Back then, children did not have as much access to digital information as they do today. The same may also be true for the consistency of indications of particular mental models. Further research is needed in this regard.

\subsection{The Perspective of Knowledge-as-Theory or Knowledge-as-Elements}

The main aim of the research conducted to date has been to confirm or refute the existence of mental models. By accepting the assumption of the fragmentarists that mental models should reveal themselves in all test questions, in order to confirm this thesis, it suffices to see how many children in all test questions marked answers relating to the same picture depicting, for example, the Earth as a sphere. Studies using latent class analysis $[13,31]$ clearly indicated that children do not adhere to one shape of the Earth. If only responses to scientific models are considered, then as few as 32 Polish children $(7.2 \%)$ ticked the scientific model in all test questions. This result was considered to prove a low consistency of mental models and thus the importance of the knowledge-as-elements perspective was raised. However, if in the evaluation of children's test answers/pictures one also takes into account those in which the Earth was presented as a sphere, then it turns out that among Polish children, 30\% marked the same shape of the Earth and 5.9\% 
marked a flat Earth (except in direct questions about the shape of the Earth). This means that almost $36 \%$ of all respondents maintain a consistent model of the shape of the Earth.

As the above figure refers to children who presented initial and scientific models, for the remaining children (2/3), it can be assumed that they are in a transitional phase. They start to realise that their existing concepts are insufficient and become insecure in their beliefs $[1,34]$. They are receptive to information received from adults. However, as they are not yet able to combine it with their personal experiences, they tolerate two different concepts next to each other (dualism). The respected Polish pedagogue and psychologist Stefan Szuman [35] explained that the development of awareness in children progresses from mindless usage of phrases heard from others to a gradual discovery of their meanings. This discovery takes place during the usage of heard expressions. According to Szuman, by verbalising information heard, a child becomes aware of it and by combining it with personal experiences, he/she constructs outlines of concepts. For example, in the testbased study, the question arose as to what extent children were guided by the experience of falling objects (the effect of gravity), and to what extent when choosing a picture they were guided only by their belief in a certain shape of the Earth and intuitions about the location of people and the ball on Earth. It is impossible to provide a clear answer based on the results of the EARTH2 test only. However, in the study in which children modelled the shape of the Earth with plasticine and placed people on it, taking into account the force of gravity, they provided explanations by saying, for example, that people do not fall because there is this force called gravity which attracts them. Without being taught about gravity, children intuitively come to understand it. They use the word gravity heard from adults to describe the phenomenon of falling objects, guessing that the force of attraction is the cause, although they cannot yet explain its workings in terms of astronomical considerations.

Dualistic views were revealed in situations where children were aware that the Earth was spherical in shape, but their personal experience of the force of attraction (gravity) referred to a flat Earth. They were not yet able to project this force onto a spherical Earth, so they used them separately: differently when the issue concerned the location of people, trees and clouds, and differently when it concerned the movement of people and balls. They used the explanation which was more convenient at the time. In this context, it is important to recognise that dualism of views is evidence that a child is undergoing a change of his or her explanations, which is a natural developmental stage indicative of a child moving from one model to another. Consistency of concepts can therefore not be expected at the transitional stage. This stage of clarification confirms the knowledge-as-elements perspective. As $36 \%$ of the examined children showed coherence of views, the remaining children seem to be in a transitional phase.

Linking intuitions to outlines of concepts seems contradictory if considered from the perspective of adult thinking, reasoning at the concrete or formal operational stages (in Jean Piaget's sense). However, it is typical of children in transition from, for example, one of the pre-operational thinking stages to the more mature concrete operational stage. Studies which determined the consistency of children's concepts [13,31] seem to have overlooked the specific nature of synthetic models. As they represent a transitional stage, they are characterised by volatility. In the study using plasticine [28], this volatility was revealed in dualistic explanations, whereas in the test-based study, it may have been revealed in the choice of pictures representing different synthetic models. However, the fact that as many as $30 \%$ of children pointed to pictures in which the Earth was depicted as a sphere means that their conceptions were consistent. These findings support the concept of mental models (knowledge-as-theory) and Vosniadou's [21] comments on the application of forced-choice tools, which limit the generation of internal models.

The study seems to confirm both the knowledge-as-theory and knowledge-as-elements perspectives. It therefore appears that both perspectives explain different stages of the same process. Consistent mental models are reflected in concepts based on personal experience (initial models) and those based on scientific knowledge (scientific models). Children presenting these models seem confident in their beliefs $[1,34]$. The knowledge-as-elements 
approach, on the other hand, explains an intermediate stage in which children combine personal experiences with information heard from adults. Synthetic models are characterised by uncertainty, when children begin to realise that their current explanation does not work and they abandon it. They seem to construct their explanations by abandoning rigid connections, so to speak, by breaking down knowledge into elements. They accept adult knowledge mindlessly [35] and in the course of processing received information (verbalising, modelling with plasticine, drawing) they solve subsequent cognitive problems, gradually constructing their knowledge. The child's uncertainty about what he or she says decreases as he or she moves towards science-like concepts. The attempt to explain the process of constructing children's knowledge by combining two theories needs to be considered and empirically confirmed, especially as the arguments of the representatives of both approaches seem to be relevant.

\section{Conclusions}

This paper presents the sequence of cognitive problems that children solve when constructing the concept of a spherical Earth. Attention to this sequence may have important implications for the organisation of effective educational interventions.

Disparities in EARTH2 test results between Dutch, Greek and Polish children point to the importance of cultural influence. This is important, as the forced-choice test has been found to be sensitive to even minor cultural differences. Further research is needed to validate or refute these conclusions.

Moreover, the high consistency of views (36\%) revealed by the analysis of the relationship between individual responses in the test is consistent with the findings of Vosniadou et al. (2004) that the use of force-choice tests limits children's choices and narrows the field of inquiry. It was concluded that the assumption made by the authors of the EARTH2 test, that consistency of concepts can only be established if all questions in the test are answered uniformly, seems to be too rigorous. Further research is needed to verify the consistency of children's explanations by assessing more subtle relations between answers in the test. It also seems important to revise views on the development of research tools and the analysis of results.

Funding: This research was funded by the National Science Centre (Poland), grant number 2017/01/X/HS6/01980.

Institutional Review Board Statement: Ethical review and approval were waived for this study, due to the study being part of a project for which ethical approval had been obtained from the National Science Centre (Poland).

Informed Consent Statement: Informed consent was obtained from all subjects involved in the study.

Data Availability Statement: Data are available on request due to restrictions, e.g., privacy or ethical. Completed child tests are not publicly available due to privacy protection of participants.

Conflicts of Interest: The funders had no role in the design of the study; in the collection, analyses, or interpretation of data; in the writing of the manuscript, or in the decision to publish the results. 


\section{Appendix A}

Table A1. Percentage of picture choices by age group.

\begin{tabular}{|c|c|c|c|c|c|c|c|c|}
\hline \multirow{2}{*}{ Question } & \multirow{2}{*}{ Country } & \multicolumn{7}{|c|}{ Mental Models } \\
\hline & & Flat Earth & & Hollow & Dual & Flattened & No Gravity & Scientific \\
\hline \multirow{3}{*}{$\begin{array}{l}\text { 1. What does the Earth } \\
\text { look like? }\end{array}$} & NL & 4.5 & & 10.3 & 2.9 & 1.3 & - & 81.0 \\
\hline & GR & 1.1 & & 2.2 & 2.2 & 0.0 & - & 94.6 \\
\hline & PL & 0.2 & & 0.0 & 0.9 & 0.2 & - & 98.6 \\
\hline \multirow{3}{*}{$\begin{array}{l}\text { 2. Which picture shows } \\
\text { best where the people live } \\
\text { on the Earth? (3) }\end{array}$} & NL & 16.1 & & 11.6 & - & 3.4 & 24.3 & 44.6 \\
\hline & GR & 12.0 & & 13.0 & - & 1.1 & 19.6 & 54.3 \\
\hline & PL & 8.0 & & 5.9 & - & 1.0 & 22.3 & 62.6 \\
\hline \multirow{3}{*}{$\begin{array}{l}\text { 3. Which picture shows } \\
\text { best where the clouds } \\
\text { are? }\end{array}$} & NL & 7.7 & & 8.2 & - & 1.6 & 37.5 & 45.1 \\
\hline & GR & 9.8 & & 16.3 & - & 0.5 & 31.5 & 41.8 \\
\hline & PL & 3.6 & & 3.8 & - & 0.2 & 31.5 & 60.8 \\
\hline \multirow{4}{*}{$\begin{array}{l}\text { 4. Which picture shows } \\
\text { best what happens when } \\
\text { a giant kicks a ball real } \\
\text { hard? }\end{array}$} & & $\begin{array}{l}\text { Falls off the } \\
\text { Earth }\end{array}$ & $\begin{array}{l}\text { Does not fall } \\
\text { off the Earth }\end{array}$ & & & & & \\
\hline & NL & 8.5 & 10.1 & 5.8 & - & 9.3 & 26.5 & 39.9 \\
\hline & GR & 7.1 & 10.9 & 6.5 & - & 5.4 & 34.8 & 35.3 \\
\hline & PL & 2.9 & 7.9 & 7.7 & - & 3.6 & 27.5 & 50.5 \\
\hline \multirow{3}{*}{$\begin{array}{l}\text { 5. Which picture shows } \\
\text { best where the trees are } \\
\text { on the Earth? }\end{array}$} & NL & 18.3 & & 9.5 & - & 4.2 & 25.5 & 42.4 \\
\hline & GR & 12.0 & & 14.1 & - & 1.1 & 30.4 & 42.4 \\
\hline & PL & 13.7 & & 7.7 & - & 1.4 & 27.7 & 49.5 \\
\hline \multirow{4}{*}{$\begin{array}{l}\text { 6. Where is the Sun at } \\
\text { night? }\end{array}$} & & Cloud & Sundown & & & & & \\
\hline & NL & 15.6 & 29.6 & 5.0 & - & - & 9.0 & 40.9 \\
\hline & GR & 3.8 & 42.9 & 7.6 & - & - & 6.0 & 39.7 \\
\hline & PL & 8.9 & 19.6 & 7.4 & - & - & 10.4 & 54.3 \\
\hline \multirow{4}{*}{$\begin{array}{l}\text { 7. What happens when } \\
\text { you walk along a straight } \\
\text { line for a very long time? }\end{array}$} & & $\begin{array}{l}\text { Falls off the } \\
\text { Earth }\end{array}$ & $\begin{array}{l}\text { Does not fall } \\
\text { off the Earth }\end{array}$ & & & & & \\
\hline & NL & 11.3 & 9.8 & 5.8 & - & 5.5 & 20.1 & 47.5 \\
\hline & GR & 3.3 & 9.8 & 10.3 & - & 1.1 & 16.8 & 58.7 \\
\hline & PL & 2.3 & 6.5 & 8.1 & - & 2.0 & 9.7 & 71.4 \\
\hline \multirow{3}{*}{$\begin{array}{l}\text { 8. Which picture } \\
\text { resembles the Earth best? }\end{array}$} & NL & 3.2 & & 5.5 & 5.5 & 4.7 & - & 81.0 \\
\hline & GR & 1.1 & & 4.9 & 0.5 & 0.5 & - & 92.9 \\
\hline & PL & 1.1 & & 0.5 & 0.0 & 1.8 & - & 96.6 \\
\hline \multirow{4}{*}{$\begin{array}{l}\text { 9. Which picture shows } \\
\text { best how night falls? }\end{array}$} & & Cloud & Sundown & & & & & \\
\hline & NL & 21.6 & 38.3 & 9.2 & - & - & 18.2 & 12.7 \\
\hline & GR & 10.3 & 40.8 & 8.7 & - & - & 19.0 & 21.2 \\
\hline & PL & 8.8 & 39.6 & 5.9 & - & - & 25.0 & 20.7 \\
\hline
\end{tabular}

\section{References}

1. Vosniadou, S.; Brewer, W.F. Mental models of the earth: A study of conceptual change in childhood. Cogn. Psychol. 1992, 24, 535-585. [CrossRef]

2. Di Sessa, A.A. Knowledge in pieces. An Evolving Framework for Understanding Knowing and Learning. In Converging PerSpectives on Conceptual Change: Mapping an Emerging Paradigm in the Learning Sciences; Amin, T.G., Levini, O., Eds.; Routledge: New York, NY, USA, 2017; pp. 9-16. ISBN 978-1-138-20540-6.

3. Clark, D.B. Longitudinal Conceptual Change in Students' Understanding of Thermal Equilibrium: An Examination of the Process of Conceptual Restructuring. Cogn. Instr. 2006, 24, 467-563. [CrossRef]

4. Frède, V. Comprehension of the night and day cycle among French and Cameroonian children aged 7-8 years. Cult. Stud. Sci. Educ. 2018, 14, 587-615. [CrossRef]

5. Bar, V.; Brosh, Y.; Sneider, C. Weight, Mass, and Gravity: Threshold Concepts in Learning Science. Sci. Educ. 2015, $24,1-14$.

6. Özsoy, S. Is the Earth Flat or Round? Primary School Children's Understandings of the Planet Earth: The Case of Turkish Children. Int. Electron. J. Elem. Educ. 2012, 4, 407-415.

7. Kampeza, M.; Ravanis, K. Transforming the Representations of Preschool-Age Children Regarding Geophysical Entities and Physical Geography. Rev. Sci. Math. Ict Educ. 2009, 3, 141-158. 
8. Nussbaum, J.; Novak, J.D. An assessment of children's concepts of the earth utilizing structured interviews. Sci. Educ. 1976, 60, 535-550. [CrossRef]

9. Sneider, C.; Pulos, S. Children's Cosmologies: Understanding the Earth's Shape and Gravity. Sci. Educ. 1983, 67, 205-221. [CrossRef]

10. Panagiotaki, G.; Nobes, G.; Banerjee, R. Children's representations of the earth: A methodological comparison. Br. J. Dev. Psychol. 2006, 24, 353-372. [CrossRef]

11. Saçkes, M.; Smith, M.M.; Trundle, K.C. US and Turkish preschoolers' observational knowledge of astronomy. Int. J. Sci. Educ. 2016, 38, 116-129. [CrossRef]

12. Panagiotaki, G.; Nobes, G.; Potton, A. Mental models and other misconceptions in children's understanding of the earth. J. Exp. Child. Psychol. 2009, 104, 52-67. [CrossRef]

13. Straatemeier, M.; van der Maas, H.L.; Jansen, B.R. Children's knowledge of the earth: A new methodological and statistical approach. J. Exp. Child. Psychol. 2008, 100, 276-296. [CrossRef] [PubMed]

14. Wellman, H.M.; Gelman, S.A. Cognitive Development: Foundational Theories of Core Domains. Annu. Rev. Psychol. 1992, 43, 337-375. [CrossRef] [PubMed]

15. Carey, S. Sources of conceptual change. In Conceptual Development: Piaget's Legacy; The Jean Piaget Symposium series; Lawrence Erlbaum Associates Publishers: Mahwah, NJ, USA, 1999; pp. 293-326. ISBN 978-0-8058-2500-8.

16. Ioannides, C.; Vosniadou, S. The Changing Meanings of Force. Cogn. Sci. Q. 2002, 2, 5-62.

17. Özdemir, G.; Clark, D.B. An Overview of Conceptual Change Theories. Eurasia J. Math. Sci. Technol. Educ. 2007, 3, 351-361. [CrossRef]

18. Vosniadou, S. Capturing and modeling the process of conceptual change. Learn. Instr. 1994, 4, 45-69. [CrossRef]

19. Murray, E.; Piaget, J.; Tomlinson, A.; Tomlinson, J. The Child's Conception of the World. Am. J. Psychol. 1931, 43, 154. [CrossRef]

20. Posner, G.J.; Strike, K.A.; Hewson, P.W.; Gertzog, W.A. Accommodation of a scientific conception: Toward a theory of conceptual change. Sci. Educ. 1982, 66, 211-227. [CrossRef]

21. Vosniadou, S.; Skopeliti, I.; Ikospentaki, K. Modes of knowing and ways of reasoning in elementary astronomy. Cogn. Dev. 2004, 19, 203-222. [CrossRef]

22. Samarapungavan, A.; Vosniadou, S.; Brewer, W.F. Mental models of the earth, sun, and moon: Indian children's cosmologies. Cogn. Dev. 1996, 11, 491-521. [CrossRef]

23. Diakidoy, I.-A.; Vosniadou, S.; Hawks, J.D. Conceptual change in astronomy: Models of the earth and of the day/night cycle in American-Indian children. Eur. J. Psychol. Educ. 1997, 12, 159-184. [CrossRef]

24. Nobes, G.; Moore, D.G.; Martin, A.E.; Clifford, B.R.; Butterworth, G.; Panagiotaki, G.; Siegal, M. Children's understanding of the earth in a multicultural community: Mental models or fragments of knowledge? Dev. Sci. 2003, 6, 72-85. [CrossRef]

25. Barnett, M.; Wagner, H.; Gatling, A.; Anderson, J.; Houle, M.; Kafka, A. The Impact of Science Fiction Film on Student Understanding of Science. J. Sci. Educ. Technol. 2006, 15, 179-191. [CrossRef]

26. Vosniadou, S. Students' Misconceptions and Science Education. Available online: https://oxfordre.com/education/view/10.109 3/acrefore/9780190264093.001.0001/acrefore-9780190264093-e-965 (accessed on 5 January 2021).

27. Vosniadou, S.; Archontidou, A.; Kalogiannidou, A.; Ioannides, C. How Greek children understand the shape of the earth: A study of conceptual change in childhood. Psychol. Issues 1996, 7, 30-51.

28. Jelinek, J.A. Children's Astronomy. Shape of the Earth, Location of People on Earth and the Day/Night Cycle According to Polish Children between 5 and 8 Years of Age. Rev. Sci. Math. ICT Educ. 2020. Forthcoming papers. [CrossRef]

29. Vosniadou, S.; Brewer, W.F. Mental Models of the Day/Night Cycle. Cogn. Sci. 1994, 18, 123-183. [CrossRef]

30. Siegal, M.; Butterworth, G.; Newcombe, P.A. Culture and children's cosmology. Dev. Sci. 2004, 7, 308-324. [CrossRef]

31. Vaiopoulou, J.; Papageorgiou, G. Primary students' conceptions of the Earth: Re-examining a fundamental research hypothesis on mental models. Presch. Prim. Educ. 2018, 6, 23. [CrossRef]

32. Yıldız, E.; Özgül, S.G.; Saçkes, M. Bütünleştïrïlmïş fen ve türkçe etkïnliklerïnïn okul öncesï çocuklarinin dünya'nin şeklï ve gece gündüz kavramlarini anlayişlarina etkïsï. Balıkesir Üniversitesi Sos. Bilimler Enstitüsü Derg. 2019, 22, 155-171. [CrossRef]

33. Vygotsky, L. Thought and Language; The MiT Press: London, UK, 1986; ISBN 978-0-262-22029-3.

34. Bryce, T.G.K.; Blown, E.J. Children's Concepts of the Shape and Size of the Earth, Sun and Moon. Int. J. Sci. Educ. 2013, 35, 388-446. [CrossRef]

35. Szuman, S. Dzieła Wybrane. Studia nad Rozwojem Psychicznym Dziecka; PWN: Warszawa, Poland, 1985. 